\title{
Padronização de um protocolo para assepsia de segmentos nodais de Phalaenopsis para clonagem in vitro
}

\author{
Fernanda Kelly Mezzalira, Betty Cristiane Kuhn
}

Universidade Tecnológica Federal do Paraná - Campus Dois Vizinhos. E-mail: fernanda mezzalira25@hotmail.com, bettykuhn@utfpr.edu.br

\section{Resumo}

A biotecnologia vegetal é uma área de elevada importância para obter organismos vegetais com características superiores aos já existentes no mercado. A clonagem é uma das ferramentas que é utilizada para essa função, seleciona-se organismos com características de interesse e realiza-se a multiplicação deste individuo, garantindo que as plantas regeneradas sejam geneticamente idênticas a matriz desejada, estabelecendo uma padronização. Sabendo que o setor de plantas ornamentais contribui de maneira expressiva com a economia e dentre as plantas ornamentais de mais estima entre os brasileiros, encontram-se as orquídeas, que vem adquirindo visibilidade cultural e um grande número de colecionadores nos últimos anos. O objetivo, do presente trabalho, foi estabelecer um protocolo de assepsia eficiente para meristemas laterais e obtenção de clones da orquídea do gênero Phalaenopsis. Para metodologia, visando a padronização de um protocolo de assepsia, foram elaborados e testados 4 tratamentos que possuíam diferentes combinações (concentração $x$ tempo) de agentes como o hipoclorito de sódio, álcool, cobre, tween e lavagem dos explantes com água destilada estéril para meristemas laterais da orquídea de gênero Phalaenopsis. Os meristemas, também conhecidos como gemas laterais, foram retirados do caule das plântulas, de suas hastes florais. Quanto a obtenção de clones, o experimento realizado consistia na inoculação dos meristemas, após processo de assepsia, em meios de cultura Knudson, contendo diferentes combinações de reguladores de crescimento, sendo utilizado uma auxina e citocinina. Os resultados obtidos mostram que, nenhum tratamento para assepsia testados neste trabalho, apresentou resultados significativos e positivos, deste modo não foi possível estabelecer, ainda, um protocolo de assepsia para meristemas laterais de orquídeas do gênero Phalaenopsis. Uma vez que todos os meristemas sofreram contaminação e oxidação. Logo, ainda não foi possível obter clones, por essa metodologia. Este trabalho serve como base inicial, para futuras pesquisas, referente a clonagem através de meristemas em Phalaenopsis.

Palavras-Chaves: Cultivo in vitro; clonagem; econômia; meristemas; Phalaenopsis.

\section{Standardization of a protocol for assepsis of nodal Phalaenopsis segments for in vitro cloning}

\begin{abstract}
Plant biotechnology san área of high importance since it has for obtaining plant organisms with characteristics superior to those already on the market. Cloning is one of the tolos that for this function, through it, organisms with characteristics of interest are selected and this individual is multiplied, ensuring that there generated plants are genetically identical to the desired matrix, establishing a standardization. Knowing that the ornamental plants sector contributes significantly to the economy and among the most esteemed ornamental plants among Brazilians, there are orchids which have acquired cultural visibility and a large number of collectors in recent years. The objective of the present work was to establish an efficient assepsis protocol for lateral meristems and to obtain clones of the orchid of the genus Phalaenopsis. For methodology, aiming at the standardization o fan asepsis protocol, 4 treatments were developed and tested with different combinations (concentration $x$ time) of agents such as sodium hypochlorite, alcohol, copper, tween and washing the explants with steriledistilled wáter for meristems of the orchid of the genus Phalaenopsis. The meristems, also known as lateral bud, were removed from the stem of the seedlings,
\end{abstract}


from their floral stems. As forobtained clones, the experiment carried out consisted of inoculating the meristems, after an asepsis process, in Knudson culture media, containing different combinations of grow thregulators, using anauxin and cytokinin. The results obtained show that, no asepsis treatments tested in this work, presented significant and positive results, so it was not posible to establish, as yet, an asepsis protocol for lateral meristem of orchids of the genus Phalaenopsis. Since all meristems suffered contamination and oxidation. There for, it was not yet posible to obtain clones, using this methodology. This work serves as aninitialbasis, for future research, regarding cloning through meristems in Phalaenopsis.

Keywords: In vitro culture; cloning; economy; meristems; Phalaenopsis.

\section{Introdução}

As orquídeas estão entre as plantas ornamentais de maior interesse econômico, pois contemplam uma variedade de combinações e formatos de flores (SEBRAE, 2015; PAULIQUEVIS, 2017; BARROS et al., 2018). A Phalaenopsis ssp., é um dos gêneros de orquídeas mais populares e comercializáveis em função de seu custo benefício, sendo acessível a todas as classes econômicas no Brasil e no mundo (LEE, 2011; COSTA, 2013; SCHOENMAKER, 2017). As orquídeas encontram-se na produção agrária de muitos países como, por exemplo, Gorontalo, Hawaii (GORONTALO, 2012), onde uma das principais fontes de renda da agricultura é a produção de orquídeas (HAWAll, 2017), assim como Holanda, Japão, Brasil e outros (SCHOENMAKER, 2017).

O mercado florícolo movimentou mais de US\$ 70 bilhões no ano de 2017, no qual somente a Phalaenopsis chegou a ter mais de duas mil plantas comercializadas por semana na Holanda (SCHOENMAKER, 2017). Segundo estimativa realizada por empresa de renome, ainda no ano de 2018, a Phalaenopsis ocupava a primeira colocação no ranking de vendas, cerca de 139 milhões de plantas (ROYAL FLORA HOLLAND, 2018). Para obtenção das plantas com mais qualidade faz-se uso da biotecnologia, que é muito empregada na propagação de orquídeas, visto sua importância e interesse econômico.

A biotecnologia é uma ciência que engloba o uso de seres vivos, ou uma parte destes, para desenvolver/obter processos e/ou produtos de interesse econômico e social (CHAER, 2012). Na área das ciências agrárias a biotecnologia, popularmente conhecida como biotecnologia vegetal, é empregada para produção de biofungicidas, bioestimulantes, controle de pragas e doenças, melhoramento genético de plantas, uso de bactérias fixadoras de nitrogênio, uso de micorrizas para elevar a produtividade de plantas, transformação genética e outras (FALEIRO; ANDRADE, 2011).

Uma das ferramentas biotecnológicas mais empregadas em plantas ornamentais é a cultura de células e tecidos vegetais, para a micropropagação in vitro das plantas (MEZZALIRA; KUHN, 2020). Diversas metodologias para o cultivo in vitro de Phalaenopsis já foram estabelecidas. Segundo dados da literatura, grande parte dos trabalhos faz uso de sua propagação por sementes, tendo meios de cultivo e parâmetros de cultivos já estabelecidos e eficientes (ZAHARA et al., 2017; MEZZALIRA; KUHN, 2020). Porém, a micropropagação via sementes não garante a padronização das plantas, uma vez que as sementes possuem um aspecto de não possuir endosperma o que dificulta sua germinação em condições naturais, e com o uso do cultivo in vitro para germinação de sementes tem-se um aumento na sua diversidade, por meio de variações somaclonais que não podem ser evitadas por esse meio (COSTA, 2013).

Para obter plantas geneticamente idênticas, uma opção é fazer uso da clonagem in vitro, essa técnica possibilita a obtenção de plantas uniformes em características como coloração, tamanhos, formas, época de floração, entre outras (KERBAUY; CHAER, 2011). Sendo o cultivo in vitro amplamente aplicado em ornamentais, para propagar mudas livres de fitopatógenos (COSTA, 2013).

$\mathrm{Na}$ literatura são raros os trabalhos que relatam o uso de clonagem em orquídeas, nos últimos anos ocorreu a padronização da clonagem da orquídea do gênero Oncidium utilizando como segmento suas folhas (MAYER et al., 2011). Outro trabalho utilizou segmentos caulinares para clonagem da orquídea do gênero Catasetum fimbriatum, em meio de cultivo Vacin e Went (1949) (NETO; SILVA, 2017). No trabalho de Chaer (2012), estabeleceu-se uma estratégia para clonar in vitro orquídeas do gênero Cattleya 
e Cymbidium, utilizando gemas laterais. Segundo Mayer et al. (2010) são poucos os trabalhos que relatam o uso de clonagem em orquídeas para sua propagação. No cultivo in vitro de plantas uma das etapas mais importantes do processo é o estabelecimento de um protocolo de assepsia eficiente, é um processo difícil de se estabelecer pois, um protocolo de uma espécie nem sempre terá os mesmos resultados para outra espécie assim como há essa diferença entre gêneros e até mesmo entre explantes de uma mesma planta, no qual o mesmo protocolo pode não ser aplicável (NETO, 2017).

Para Soccol (2013), a demanda por clones de Phalaenopsis é crescente, em função dos consumidores cada vez mais exigentes em questão de qualidade e características. Entretanto, "A grande dificuldade está no estabelecimento in vitro do explante, na oxidação dos explantes e baixa taxa de repicagem" (SOCCOL, 2013). Os problemas encontrados relatados são o alto custo de produção de mudas e a dificuldade de clonagem de orquídea do gênero Phalaenopsis.

Diante do exposto, sabendo da importância econômica e que ainda não se tem um protocolo eficiente para a assepsia e a clonagem da orquídea do gênero Phalaenopsis. 0 presente trabalho, teve como objetivo, estabelecer um protocolo eficiente de assepsia de meristemas laterais e obtenção de clones da orquídea do gênero Phalaenopsis. Através do uso de agentes desinfetantes, já utilizados na literatura, e sua inoculação em meio de cultivo acrescido de reguladores de crescimento. Somente após um protocolo eficiente e padronizado para uso de segmentos nodais laterais será possível estabelecer protocolos e indicação de meios adequados para clonagem, sem percas por contaminação e oxidação dos materiais.

\section{Metodologia}

Experimento: Trata-se da clonagem a partir de segmentos nodais da orquídea Phalaenopsis (Figura 1), esse explante foi selecionado após pesquisa literária sobre clonagem em Cattleya e Cymbidium utilizando gemas laterais de hastes estioladas (CHAER, 2012). As Phalaenopsis utilizadas neste trabalho tinham vida adulta de 3 anos. Esse trabalho foi realizado no Laboratório de cultivo in vitro da Universidade Tecnológica Federal do Paraná, Campus Dois Vizinhos.

Figura 1. Inoculação in vitro de meristema lateral de Phalaenopsis em meios de cultivo com combinações de BAP/ANA.

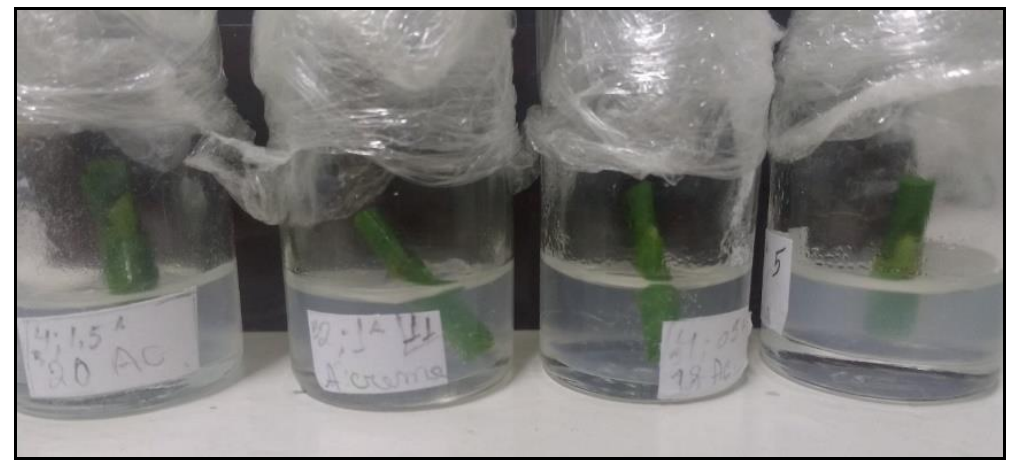

Fonte: Autor (2020).

Quatro tratamentos de assepsias foram testados em combinações distintas. Esses tratamentos foram definidos a partir de trabalhos anteriores realizados para a assepsia de sementes de Phalaenopsis e por trabalhos que utilizam cobre para o controle de fungos, antracnose e bactérias (EMBRAPA, 2004; MEZZALIRA; KUHN, 2020).

Tratamento 1:

(1) Lavagem dos meristemas por 20 minutos em água destilada com tween;

(2) Imersão por 10 minutos em álcool $70 \%$ com agitação;
(3) Imersão por 10 minutos em solução de hipoclorito de sódio a 50\% com agitação; e

(4ㅇ) Tríplice lavagem com água destilada estéril.

\section{Tratamento 2:}

(19) Lavagem dos meristemas por 20 minutos em uma mistura de água destilada com tween e cobre 5\%;

(2) Imersão por 10 minutos no álcool 70\% com agitação; 
(3)) Imersão por 10 minutos em solução de hipoclorito de sódio $50 \%$ com agitação; e estéril.

(4ㅇ) Tríplice lavagem com água destilada

\section{Tratamento 3:}

(19) Lavagem dos meristemas por 20 minutos em uma mistura de água destilada com tween e cobre 5\%;

(2ํ) Imersão por 10 minutos em álcool $70 \%$ com agitação;

(3) Imersão por 10 minutos em solução de hipoclorito de sódio a $60 \%$ com agitação; e

(4ㅇ) Tríplice lavagem com água destilada estéril.

\section{Tratamento 4:}

(19) Lavagem dos meristemas por 20 minutos em água destilada e tween;

(2ํ) Imersão por 10 minutos em álcool $70 \%$ com agitação;

(3)) Imersão por 10 minutos em solução de hipoclorito de sódio $60 \%$ com agitação;

(4ㅇ) Imersão por 10 minutos em solução de cobre a $10 \%$ com agitação; e estéril.

(5ํ) Tríplice lavagem com água destilada

Meios de cultura para clonagem de meristemas laterais. Foram realizados 20 tratamentos, que consistiam em combinações variadas de reguladores de crescimento vegetal sendo eles o ácido naftalenoacético (ANA), uma auxina, e 6benzilaminopurina (BAP), uma citocinina, acrescidas no meio Knudson (1946) em sua força completa com $20 \mathrm{gL}^{-1}$ de sacarose, utilizando ágar bacteriológico na concentração de $4 \mathrm{gL}^{-1} \mathrm{e}$ o pH do meio foi corrigido para 7,0. As combinações testadas se encontram na tabela 1 , essas combinações foram estabelecidas após pesquisa literária sobre o uso destes reguladores para melhorar a regeneração e o crescimento de orquídeas, o BAP e o ANA são os reguladores mais utilizados no cultivo in vitro de orquídeas e as pesquisas variam as concentrações nessa faixa de uso para estes reguladores (SOARES et al., 2010; RODRIGUES, 2014; CHAVES et al., 2015; RUAS, 2019).

Tabela 1. Combinações de BAP/ANA em diferentes concentrações para 20 tratamentos utilizados nos testes da clonagem in vitro a partir de meristema lateral de Phalaenopsis

$\begin{array}{llllll} & \text { ANA }\left(\mathbf{m g L}^{-\mathbf{1}}\right) & \mathbf{0} & \mathbf{0 , 5} & \mathbf{1 , 0} & \mathbf{1 , 5} \\ \text { BAP }\left(\mathrm{mg} \mathrm{L}^{-\mathbf{1}}\right) & \mathbf{0} & \text { T 1 } & \text { T 2 } & \text { T 3 } & \text { T 4 } \\ & \mathbf{1 , 0} & \text { T 5 } & \text { T 6 } & \text { T 7 } & \text { T 8 } \\ & \mathbf{2 , 0} & \text { T 9 } & \text { T 10 } & \text { T 11 } & \text { T 12 } \\ & \mathbf{3 , 0} & \text { T 13 } & \text { T 14 } & \text { T 15 } & \text { T 16 } \\ & \mathbf{4 , 0} & \text { T 17 } & \text { T 18 } & \text { T 19 } & \text { T 20 }\end{array}$

Fonte: Autor (2020).

Após os processos de assepsia dos segmentos nodais, os mesmos eram inoculados nos meios de cultura previamente autoclavado por 20 minutos a $120{ }^{\circ} \mathrm{C}$ e um atm de pressão. Os segmentos nodais permaneciam na sala de cultivo com temperatura de $\pm 25^{\circ} \mathrm{C}$ e fotoperíodo de 16 horas com lâmpada de LED branca tubular de 18 Watts da marca Galaxy LED. Trabalhos descrevem que estes parâmetros já estabelecidos são uma boa combinação para o crescimento de Phalaenopsis (DONHA et al., 2019; MEZZALIRA; KUHN, 2020). A primeira avaliação ocorreu após sete dias da inoculação. Foram utilizados frascos de ampicilina com $3 \mathrm{~mL}$ de meio de cultura em cada. Os tratamentos foram realizados em triplicata.

As variáveis analisadas consistiram na observação de contaminação ou não dos explantes após processo de assepsia, e brotação nos meios de cultura. Os dados foram submetidos à análise de variância $p<(0.05)$ e as médias comparadas pelo teste Tukey $\mathrm{p}<(0.05)$ utilizando programa SASM-Agri (CANTERI et al., 2001).

\section{Resultados e Discussão}

Após três dias foi possível observar o início das oxidações seguidas das contaminações dos meios de cultivo, ao fim dos 7 dias de inoculação todos os explantes já apresentavam completa tomada pela contaminação. Assim, não foi possível estabelecer um protocolo de assepsia adequado para os meristemas laterais de orquídeas do gênero Phalaenopsis, uma vez que todas as inoculações realizadas em meio de cultivo tiveram esses problemas de contaminação e oxidação. Neste experimento, foram perdidos $100 \%$ dos meristemas (Figura 2). Visualmente, não houve diferença entre os meios na questão da contaminação fúngica e/ou bacteriana pois todos apresentaram contaminação e para a oxidação verificou-se que os tratamentos apresentavam graus de oxidação em função da quantidade de 
reguladores adicionados ao meio, quanto maior a concentração maior o escurecimento do meio, assim como visto no trabalho de Giatti e Lima (2007).

Figura 2. Contaminação de meristemas laterais de Phalaenopsis, após testes de assepsia.

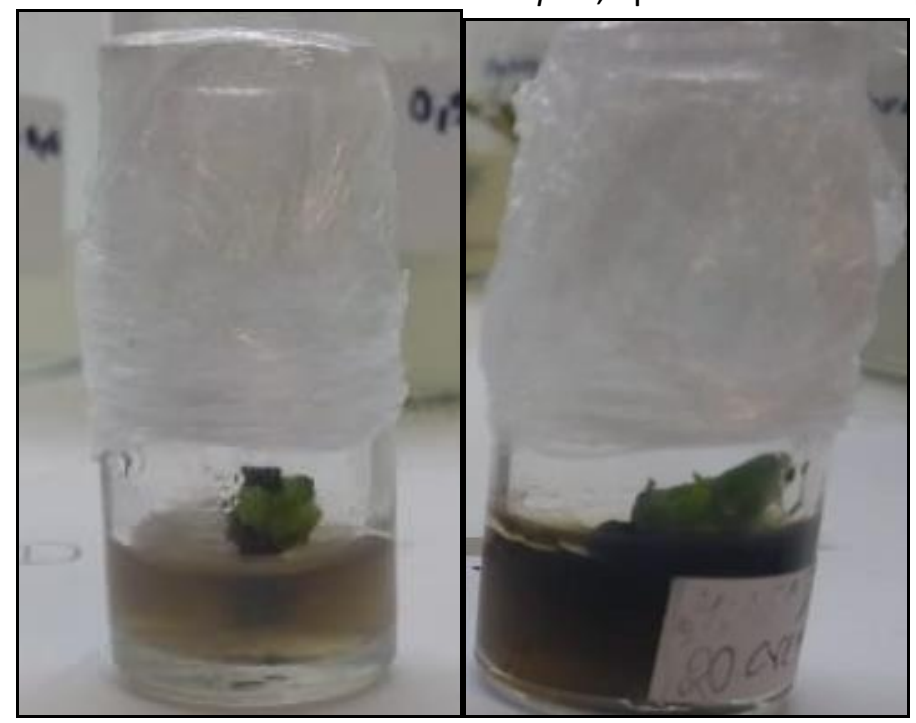

Fonte: Autor (2020).

A oxidação tem como origem a formação/desenvolvimento de complexos fenólicos. Neste trabalho não foi utilizado aditivos para controlar a oxidação do meio, mas sugerimos que em trabalhos futuros sejam testados o uso de ácido cítrico ou ácido ascórbico (SOCCOL, 2013).

Os agentes utilizados para assepsia do material são amplamente utilizados na assepsia em orquídeas de demais gêneros, porém com sementes. No trabalho de Chaer (2012) as sementes de Cattleya foram desinfestadas com a imersão em hipoclorito de sódio 20\% (v/v) por 15 minutos com gotas de detergente tween, seguida de tríplice lavagem com água destilada autoclavada. Para Mezzalira e Kuhn (2018), na germinação de sementes de Phalaenopsis a desinfestação ocorreu com uso de hipoclorito de sódios $20 \%(\mathrm{v} / \mathrm{v})$ por 5 minutos, seguido do uso de álcool $70 \%$ por 5 minutos e tríplice lavagem com água destilada autoclavada.

Protocolos eficientes de assepsia de meristemas, preferencialmente de baixo custo e mínima indução de variação somaclonal, é uma necessidade entre os produtores (SOCCOL, 2013). Em função deste apelo econômico, os agentes mais empregados são o hipoclorito de sódio e o álcool, pois, são de fácil acesso e de baixo custo.

Encontra-se na literatura, informações referentes ao uso do meio de cultura Vacin e
Went (1949) com acréscimo de $150 \mathrm{ml} / \mathrm{L}$ de água de coco, como meio de cultura indicado para a clonagem de Phalaenopsis (SOCCOL, 2013). Entretanto, Mezzalira e Kuhn (2020) relatam que - meio de cultura mais indicado para Phalaenopsis é o uso do meio Knudson acrescido de suco de cenoura $10 \%(\mathrm{v} / \mathrm{v})$. Esse resultado foi obtido após teste com 4 tratamentos, sendo eles o tratamento 1 Meio MS básico, o tratamento 2 Meio MS com o dobro da concentração básica (MS 2x), o tratamento 3 Meio Knudson $+10 \%$ (v/v) Suco de Cenoura e o tratamento 4 Meio Knudson + BAP + ANA (MEZZALIRA; KUHN, 2020). $O$ meio de cultura propicia $O$ melhor desenvolvimento das plantas e reduz os índices de contaminação e oxidação. Assim como Dronk (2004) cita o uso de meio Knudson para Phalaenopsis, e Araújo et al. (2006) diz que muitos autores sugerem o meio Vacin e Went para os seguintes gêneros de orquídeas: Cattleya, Encyclia e Oncidium.

Quanto o uso de reguladores de crescimento é muito utilizado, em diversos trabalhos, sendo citados na organogênese da Phalaenopsis por Takuhara e Mii (1993), e na obtenção de Phalaenopsis a partir de gemas laterais no meio de cultura New Dogashima, com adição de $0,1 \mathrm{mgL}^{-1} \mathrm{ANA}$ e $1,0 \mathrm{mgL}^{-1}$ BAP. Entretanto, um trabalho posterior mostrou o uso do meio de cultura New Dogashima específico 
para regeneração de folhas estilionadas (MINAMIGUCHI; NETO, 2007), para Ulisses et al. (2016) que cultivava Phalaenopsis in vitro, o meio de cultura Murashige e Skoog (1962) mostrou resultados superiores ao meio New Dogashima. Franceschi (2013) relatou que não foi possível obter regeneração de folhas de Phalaenopsis por meio do meio New Dogashima. Para Kosir et al. (2004) a multiplicação da Phalaenopsis foi obtida com uso de $2 \mathrm{mgL}^{-1}$ de BAP e $0,5 \mathrm{mgL}^{-1}$ de ANA com uso de meio de cultura comercial, adquirida da Sigma aldrich.

A escolha do explante a ser utilizado, também é um fator que interfere no sucesso da clonagem. Segundo Chaer (2012) estiolar o caule das hastes de orquídea, de modo a se isolar as gemas (meristemas) laterais causaria uma alteração hormonal das auxinas e citocininas, trazendo como benefício uma promoção do desenvolvimento dessas gemas. Quando isolados e inoculados em presença de luz, o processo de regeneração de uma planta completa é acelerado. Em seu trabalho com orquídeas do gênero Cattleya, constatou-se que a presença do hormônio giberelina age com a liberação das gemas e seu alongamento. Para a liberação das gemas, em cultivo no escuro, o uso de etileno demonstrou bons resultados. Porém, quando comparado dois gêneros de orquídeas, Cattleya e Cymbidium, o uso do etileno mostrou fenótipos distintos entre elas. Deste modo, pode-se constatar que o protocolo eficiente para um gênero não demonstrara necessariamente resultados positivos para outro gênero.

Os meristemas podem levar ao desenvolvimento de todos os órgãos de uma planta, por serem constituídos por grupos de células que mantêm caracteres de tecidos embrionários (LYNDON, 1990).

Em função dos resultados obtidos nesse experimento, sugere-se que maiores estudos sejam realizados quanto a assepsia dos meristemas da orquídea Phalaenopsis, para que seja possível futuramente obter clones. Sem estabelecer o processo de assepsia, não foi possível realizar os experimentos da clonagem in vitro de Phalaenopsis a partir de meristemas laterais, nos 20 tratamentos estabelecidos para teste com combinação de BAP/ANA.

Para que a clonagem seja eficiente, é necessário se ater ao tempo de uso dos explantes, a idade e que tipo de explantes serão utilizados, além do cuidado com o uso de substâncias que induzam divisões celulares e que, por consequência podem causar variação somaclonal indesejável (CHAER, 2012). Assim, é preciso maiores estudos e pesquisas quanto a clonagem de orquídeas e por fim o desenvolvimento de protocolos eficientes, que propiciem informações essenciais sobre os diversos modos passiveis de uso na clonagem (CHAER, 2012).

\section{Conclusões}

No presente trabalho não foi possível estabelecer um protocolo eficiente de assepsia para segmentos nodais de Phalaenopsis para sua clonagem. Nenhuma das combinações testadas teve bom resultado. Sugere-se a partir deste estudo que demais trabalhos sejam realizados em busca de uma padronização que seja eficiente.

Indica-se o uso de ácido ascórbico ou ácido cítrico suplementando os meios de cultivo para minimizar os problemas com oxidação e indica-se o uso do meio Knudson acrescido de suco de cenoura $10 \%(\mathrm{v} / \mathrm{v})$ para evitar a contaminação dos explantes.

\section{Referências}

ARAÚJO, G.; PASQUAL, A.; VILLA, M.; et al. Água de coco e polpa de banana no cultivo in vitro de plântulas de orquídea. Revista Ceres, v.53, n.310, p.608-613, 2006. https://www.redalyc.org/articulo.oa?id=3052266 75002

BARROS, F. et al. Checklist of the Orchidaceae from the state of Mato Grosso do Sul, Brazil. Iheringia - Serie Botanica, v.73, p.287-296, 2018. $\underline{10.21826 / 2446-8231201873 s 287}$

CANTERI, M. G.; et al. SASM-AGRI - sistema para análise e separação de médias em experimentos agrícolas pelos métodos Scott-Knott, Tukey e Duncan. Revista Brasileira de Agrocomputação, v.1, n.2, p.18-24, 2001. https://www.embrapa.br/busca-de-publicacoes//publicacao/512901/sasm-agri---sistema-paraanalise-e-separacao-de-medias-emexperimentos-agricolas-pelos-metodos-scott--knott-tukey-e-duncan

COSTA, M. A. P. de C.; et al. Micropropagação de orquídea. In: JUNGHANS, T. G.; SOUZA, A. da S. (Ed.). Aspectos Práticos da Micropropagação de Plantas. 2. ed. Brasília - DF: Embrapa, 2013, p.373-392. 
CHAER, L. Estudo para o estabelecimento de uma nova estratégia de clonagem in vitro de Cattleya e Cymbidium (Orchidaceae) por meio da utilização de gemas laterais de caules estiolados. 2012. $120 \mathrm{f}$. Monografia (mestrado) Área de botânica, Universidade de São Paulo, 2012.

CHAVES, C. F.; et al. Regeneração in vitro de Cattleya nobilior Indl (orchidaceae) utilizando diferentes concentrações de sacarose e benziladenina. Enciclopédia Bioesfera, 2015, dói: http://dx.doi.org/10.18677/Enciclopedia Biosfer a 2015029.

DONHA R. M. A.; et al. Crescimento in vitro de Phalaenopsis h-sin sunflower em diferentes meios de cultura e níveis de $\mathrm{pH}$. Revista em Agronegócio e meio ambiente, v.12, n.2, p.351362, 2019. https://doi.org/10.17765/21769168.2019v12n2p351-362

DRONK, A. G. Meios de cultura e condições de luminosidade para cultivo in vitro de Cattleya amethystoglossa. 2004. 45f. Monografia (mestrado) - Área de botânica, Universidade Federal do Paraná, 2004.

EMBRAPA. Cultivo da Videira. Embrapa SemiÁrido, sistema de produção 1, 2004.

FALEIRO, F. G.; ANDRADE, S. R. M. Biotecnologia: estado da arte e aplicações na agropecuária. Planaltina, DF: Embrapa Cerrados, p.730, 2011.

FRANCESCHI, C. R. B. Conservação de sementes e micropropagação de orquídeas da mata atlântica utilizando a técnica "thin cell layer". 2013. 112f. Monografia (Mestrado) Área de botânica, Universidade Federal do Paraná, 2013.

GIATTI, A.; LIMA, G. P. P. Ação do BAP na regeneração in vitro de $B L C$ owen holmes ponkan $X$ Brassavola digbiana $\mathrm{N}^{\circ}$ 2. Ciênc. agrotec., Lavras, v.31, n.5, p.1279-1285, 2007. https://www.scielo.br/pdf/cagro/v31n5/01.pdf

\section{Gorontalo. Britannica}

EncyclopædiaBritannica, alo. Acessado 12/05/20.

Hawaii. Britannica

EncyclopædiaBritannica,
Academic, $4 \quad$ Mai. /place/Goront Academic, 2 Fev.
2017. https://www.britannica.com/place/Hawaiistate. Acessado 12/05/20.

KERBAUY, G. B.; CHAER, L. Micropropagação comercial de orquídeas: Conquistas, desafios e perspectivas. In: Gerald, L. T. S. Biofábrica de plantas: produção industrial de plantas in vitro. São Paulo: Antiqua, p.178-205, 2011.

KOSIR, P.; SKOF, S.; LUTHAR, Z. Direct shooter generation fron nodes of Phalaenopsis orchids. Acta Agricultura e Slovenica, v.83, n.2, p.233242, 2004. 10.13140/2.1.1226.2086

KNUDSON, L. A new nutrient solution for the germination of orchid seed. American Orchid Society Bulletin, v.14, n.2, p.214-217, 1946.

LEE, L. L. Biofábrica de Phalaenopsis. In: Lee TSG (Ed.) Biofábrica de plantas: Produção industrial de plantas in vitro. São Paulo, Antiqua. p.150-175. 2011.

LYNDON, R. F. Plant Development - The Cellular basis. Cambridge: University Press, 1990.

MAYER, J. L. S.; CARDOSO-GUSTAVSON, P.; APPEZZATO-DA-GLÓRIA, B. Colleters in monocots: new record for Orchidaceae". Flora Elsevier, vol.206, n.3, 2011. https://doi.org/10.1016/j.flora.2010.09.003

MAYER, J. L. S; STANCATO, G. C.; APPEZZATO-DAGLÓRIA, B. Direct regeneration of Protocorm-Like Bodies (PLBs) in lea fapex of Oncidium flexuosum Sims (Orchidaceae)". Plant Cell, Tissue and Organ Culture, v.103, p.411-416, 2010. 10.1007/s11240$\underline{010-9782-9}$

MEZZALIRA, F. K.; KUHN, B. C. Uso de ferramentas da bioinformática para determinação dos possíveis efeitos do $\beta$-caroteno no cultivo in vitro de Phalaenopsis. Colloquium Agrariae, v.16, n.2, p.101-113, 2020. 10.5747/ca.2020.v1.n6.a364

MEZZALIRA, F. K.; KUHN, B. C. O prestígio da família Orchidaceae para o mundo: Artigo de revisão. Pleiade, v.13, n.29, p.58-68, 2019. https://doi.org/10.32915/pleiade.v13i29.642 MEZZALIRA, F. K.; KUHN, B. C. Cultivo de Phalaenopsis hybrida. XXIII SICITE - Seminário de Iniciação Científica e Tecnológica. Apucarana-PR, 2018. 
MINAMIGUCHI, J; NETO, M. Embriogênese somática direta em folhas de Phalaenopsis: Orchidaceae. Colloquium Agrarie, v.3, n.1, p.713, 2007. 10.5747/ca.2007.v03.n1.a22

MURASHIGE, T., SKOOG, F. A revised medium for rapid growth and bioassays with to bacco tissue cultures. Physiologia Plantarum, v.15 p.473-497, 1962. https://doi.org/10.1111/j.13993054.1962.tb08052.x

NETO, A. A. C.; SILVA, P. P. A. Recursos genéticos vegetais: aplicações do cultivo in vitro. VII Botânica no Inverno 2017 - São Paulo: Instituto de Biociências da Universidade de São Paulo, Departamento de Botânica, p.332, 2017.

PAULIQUEVIS, M. Mercado de flores sobrevive à crise. Estado de Minas: Economia, 2017. Disponível em: https://www.em.com.br/app/noticia/economia/ 2017/08/25/internas economia,895049/mercad o-de-flores-sobrevive-a-crise.shtml. Acesso em: $25 / 10 / 2019$.

RODRIGUES, A. A. J. Estiolamento in vitro de Cattleya labiata e Phalaenopsis sp. 2014. 73f. Monografia (Mestrado) Área de fitotecnia, Universidade Federal do Ceará, 2014.

ROYAL FLORA HOLLAND. Annual report 2018: Top 5 Kamerplanten. Disponível em: https://www.royalfloraholland.com/en/aboutfloraholland/who-we-are-what-we-do/facts-andfigures/annual-reports. Acesso em: 22/04/2019.

RUAS, I. L. Cultivo in vitro de orquídeas nativas do brasil: aspectos fisiológicos, anatômicos e genéticos. 2019. 79f. Monografia (Mestrado) Área de recursos genéticos vegetais, Universidade Estadual de Feira de Santana, 2019.

SEBRAE. Flores e plantas ornamentais do Brasil: série estudos mercadológicos. Vol. 1, Brasília/DF, 2015.

SOARES, J. D. R.; et al. Estiolamento e luz artificial no cultivo in vitro de orquídeas nativa e híbrida. Ciência Rural, v.40, n.9, p.1941-1947, 2010. ttps://doi.org/10.1590/S0103$\underline{84782010005000146}$

SOCCOL, J. J. Rosas, orquídeas, hortênsias e campânula - pesquisas e possibilidades de inovação avaliadas em Lages-SC e em Arujá - SP. 2013. 64f. Relatório de Estágio, Universidade Federal de Santa Catarina, 2013.

SCHOENMAKER, K. Boletim Informativo Ibraflor. v. 81, 2017.

TAKUHARA, K.; MII, M. Micropropagation of Phalaenopsis and Doritaenopsis by culturing shoot tips of flower atalk buds. Plant Cell Reports, v.13, p.7-11, 1993. 10.1007/BF00232306

ULISSES, C.; et al. Indução e histologia de embriões somáticos primários e secundários do híbrido Phalaenopsis classicspottedpink (Orchidaceae). Acta biológica colombiana, v.21, n.3, p.571-580, 2016. 10.15446/abc.v21n3.50032

Vacin, E; Went, F. W. Some $\mathrm{pH}$ changes in nutrientsolution. Bottanical Gazette, v.110, p.605-613, 1949.

https://www.jstor.org/stable/2472666

ZAHARA, M; et. al. The Effects of Different Media, Sucrose Concentrations and Natural Additives on Plantlet Growth of Phalaenopsis Hybrid 'Pink'. Brazilian Archives of Biology and Technology. v.60: el160149, Jan/Dez 2017. ttps://doi.org/10.1590/1678-4324-2017160149 